\title{
PERKEMBANGAN DAN PENGELOLAAN PERIKANAN LEMURU, Sardinella lemuru Bleeker 1853 DI SELAT BALI
}

\author{
Subhat Nurhakim" dan I Gede Sedana Merta")
}

\begin{abstract}
ABSTRAK
Perikanan lemuru di Selat Bali berkembang sejak tahun 1974, di mana pada tahun itu terdapat 10 unit pukat cincin. Keberhasilan alat tangkap ini menyebabkan jumlahnya terus bertambah dengan pesat, sehingga perlu diambil langkah-langkah untuk membatasi perkembangannya lebih jauh. Pada tahun 1977 jumlah pukat cincin yang beroperasi sebanyak 100 unit. Untuk mencegah bertambahnya pukat cincin yang beroperasi, dikeluarkan Surat Keputusan Bersama (SKB) antara Pemerintah Daerah Jawa Timur dan Bali. SKB ini membatasi jumlah pukat cincin yang boleh beroperasi di Selat Bali hanya 100 unit. Jumlah 100 unit yang ada dialokasikan untuk Jawa Timur 50 unit dan untuk Bali 50 unit. Kemudian SKB ini terus diperbaharui, dan yang terakhir dikeluarkan pada tahun 1992. Menteri Pertanian mengeluarkan peraturan SK. No. 123/KPTS/UM/3/ 1975 tentang Ketentuan Besarnya Mata Jaring pukat cincin yang boleh beroperasi sebesar 1 inci. Menurut nelayan, menggunakan mata jaring 1 inci pada bagian kantong menyebabkan ikan-ikan sempenit "gilled" (macok), sehingga mereka tidak mau mengikutinya dan tetap menggunakan mata yang besarnya $3 / 4$ inci. Sementara itu, produksi ikan lemuru sejak tahun 1974 terus naik dan sampai tahun 2002 sangat berfluktuasi, mencapai produksi yang paling rendah tahun 1986 dan yang tertinggi tahun 1991. Ukuran panjang ikan lemuru sejak tahun 1997 terus menurun, dari $16,61 \mathrm{~cm}$ menjadi $13,31 \mathrm{~cm}$ yang tercatat tahun 2003 .
\end{abstract}

ABSTRACT: Management and development of lemuru fisheries, Sardinella lemuru Bleeker 1853 in Bali Strait. By: Subhat Nurhakim dan I Gede Sedana Merta

Purse seine for lemuru has developed since 1974, started with only 10 unit. The success of using purse seine, made the numbers of purse seine rapidly increasing. To avoid its further increasing, the provincial government of Jawa Timur and Bali established first Joint Management Decree in 1977. Then this document had been revised three times, and the last document was issued in 1992. Ministry of Agriculture issued Decree No. 123/KPTS/UM/3/1975 regarding the mesh size of purse seine bag, that must be 1 inch. The fishermen did not comply this decree, and remained using mesh size of $3 / 4$ inch, because according to them, by using 1 inch mesh size, the small lemuru (sempenit) were gilled, made it was very difficul to clean the net. Meanwhile, since 1974 the lemuru production was rapidly increasing, and until 2002 was highly fluctuated, reaching the lowest production in 1986 and the highest in 1991. The average size of the fish caught tends to decrease from $16.61 \mathrm{~cm}$ in 1977 to only $13.31 \mathrm{~cm}$ in 2003.

KEYWORD: lemuru, management, development, Bali Strait

\section{PENDAHULUAN}

Pengelolaan perikanan laut menghadirkan suatu campuran masalah biologi, ekonomi, sosial, dan politik yang sangat kompleks (Gulland, 1974; 1977). Dalam dekade terakhir ini, masalah ini mendapat perhatian yang semakin besar, karena tekanantekanan yang terus bertambah terhadap stok-stok ikan dunia, dan kepedulian dengan pemanfaatan yang benar pada lingkungan, terutama berkenaan dengan pemanenan ikan yang rasional di laut.

Secara historis, tujuan utama dari pengelolaan perikanan adalah untuk mengkonservasi stok di perairan (King, 1995). Dalam perikanan modern, tujuan ini diperluas dengan menambahkan tujuan ekonomi, sosial dan lingkungan seperti kesejahteraan nelayan, efisiensi ekonomi, alokasi sumber daya, dan perlindungan lingkungan. Dengan demikian, tujuantujuan pengelolaan secara luas dapat dicapai yang meliputi konservasi sumber daya perikanan dan lingkungannya.
Beberapa teknik pengelolaan perikanan yang biasanya diterapkan adalah (Gulland, 1971; Tait, 1981):

1. Penutupan musim penangkapan

2. Penutupan daerah pemijahan

3. Pembatasan ukuran ikan yang tertangkap

4. Pembatasan alat:

a. Mengendalikan selektivitas alat

b. Menentapkan "fishing power"

5. Menentukan kuota hasil tangkapan

a. Suatu kuota tunggal yang menyeluruh

b. Kuota yang dialokasikan, misalnya, kepada kapal-kapal, pabrik-pabrik, atau kelompokkelompok yang lain

6. Pengawasan terhadap jumlah penangkapan:

a. Pembatasan jumlah kapal

b. Pembatasan jumlah penangkapan oleh masingmasing kapal

Lemuru adalah salah satu sumber daya yang berharga di Indonesia. Hasil pengkajian stok menunjukkan bahwa potensi lestari (MSY) ikan

\footnotetext{
Peneliti pada Pusat Riset Perikanan Tangkap, Jakarta

* Peneliti pada Balai Riset Perikanan Laut, Jakarta
} 
Karena lemahnya penegakan hukum dari pelaksanaan dan pengawasan SKB tersebut, maka jumlah pukat cincin yang beroperasi di Selat Bali terus bertambah, sehingga SKB terus diperbaharui sampai beberapa kali. Disamping itu, tidak ada pengaturan penangkapan ikan sempenit, sehingga ikan sempenit yang tertangkap berkisar antara $0,5-28,4 \%$ atau ratarata $8,1 \%$ selama periode 1984-1989. Ini sama dengan persentase yang disarankan sebanyak $8,0 \%$ oleh Sadhotomo (1991) agar tidak mempengaruhi produktivitas pukat cincin yang beroperasi.

Dalam mengimplementasikan teknik-teknik pengelolaan tersebut, perlu dilakukan pemantauan perikanan lemuru secara hati-hati, mengumpulkan data hasil tangkapan dan upaya penangkapan secara rutin, dimana memungkinkan mendapatkan dugaan kelimpahan secara independen (Csirke, 1977).

\section{Perkembangan Perikanan Lemuru}

\subsection{Perkembangan armada dan alat tangkap}

Pada tahun 1974 dilakukan percobaan penangkapan oleh Pernerintah Daerah Banyuwangi bekerja sama dengan Dinas Perikanan dengan menurunkan alat tangkap pukat cincin sebanyak 10 unit. Pemerintah Daerah memutuskan untuk memberikan kredit kepada kelompok-kelompok nelayan anggota KUD yang beranggotakan 12 orang. Karena hasilnya sangat baik, banyak masyarakat yang menjual tanah, sawah, dan ladang garamnya untuk memiliki alat tangkap pukat cincin. Sejak saat itu perikanan pukat cincin berkembang, menjadi 44 unit pada tahun 1975 dan bertambah lagi menjadi 119 unit pada tahun 1977. Karena keinginan masyarakat tetap besar untuk memiliki pukat cincin dan penegakan hukum dari SKB yang dikeluarkan kurang memadai, maka jumlah pukat cincin terus bertambah menjadi 133 unit pada tahun 1978. Pada tahun 1983 jumlah pukat cincin sudah menjadi 200 unit dan pada tahun 1985 menjadi 273 unit. Sejak itu, tampak bahwa perubahan jumlah pukat cincin tidak secepat yang terjadi pada tahun-tahun sebelumnya. Pada tahun 1990 jumlah pukat cincin yang beroperasi dari Bali hanya 67 unit, padahal jumlah SIUP yang dialokasikan untuk Bali sebanyak 83 unit.

Pada awal-awal perkembangannya, satu unit pukat cincin terdiri dari satu buah perahu jaring berukuran $(P x L x D)=11 \times 2,7 \times 1,5$ meter (ABK 8-11 orang), perahu selerek yang berukuran $(P \times L \times D)=13 \times 2,8 \times 1,5$ meter (ABK 13-15 orang), masing-masing menggunakan dua motor luar, satu di sebelah kiri dan satu di sebelah kanan dengan kekuatan masing-masing 13-130 PK (Barus \& Nasution, 1982). Satu buah perahu kecil (pelak) berukuran $\mathrm{P} x \mathrm{~L} \times \mathrm{D}=4 \times 0,6 \times 0,35$ meter ( $\mathrm{ABK} 1$ orang), tidak menggunakan mesin, digunakan sebagai tempat lampu-lampu petromax (4-5 buah lampu). Kemudian dalam perkembangannya tidak lagi menggunakan pelak dalam operasinya. Para "fishing master" hanya melihat kilatan gerombolan ikan lemuru sebelum mengoperasikan jaringnya.

Ternyata unit-unit pukat cincin yang beroperasi bertambah besar, baik ukuran perahu, kekuatan mesin (HP) maupun ukuran jaringnya yang bertambah panjang dan dalam (technological creep), dan satusatunya yang tidak pernah berubah dari sejak awal perkembanoan pukat cincin sampai sekarang adalah besarnya mata jaring, $3 / 4$ inci. Terus bertambahnya bobot kapal (GT) dalam periode 1985-1999 meskipun jumlah kapal relatif sama, juga diperlihatkan oleh Ghofar et. al. (2000). Lebih jauh disampaikan selain dari mengendalikan upaya melalui pembatasan jumlah lisensi (SIUP), juga perlu dijamin agar tidak ada kenaikan kekuatan mesin. Jika kekuatan mesin dipertahankan konstan, maka ukuran kapal, jaring dan jumlah nelayan kelihatannya akan tetap konstan. Panjang jaring pukat cincin ada yang berukuran 300 450 meter dengan dalam berkisar antara 75-105 meter. Hasil pengukuran 30 unit kapal pukat cincin secara acak, hanya dua kapal dengan GT di bawah 30 GT $(26,76-28,50$ GT), sedangkan 28 kapal lainnya $>30$ GT $(93,3 \%)$, dengan kisaran antara $3 i, 30-46,45$ GT). Karena jaring bertambah dalam, maka daerah operasinya menjadi agak ke tengah, pada kedalaman paling sedikit kira-kira 70 meter. Yang terus tidak pernah berubah adalah besar mata jaring bagian kantongnya (1 inci). Perkembangan jumlah pukat cincin sejak 1993-2002 disajikan secara rinci dalam Tabel 1

Dilihat dalam Tabel 1 di atas ternyata jumlah pukat cincin yang ada lebih sedikit dari jumlah SIUP yang disediakan. Walaupun jumlahnya lebih sedikit, tetapi karena kapal-kapal bertambah besar, kemungkinan upaya efektifnya akan tetap tidak berubah.

Perkembangan jenis alat-alat lainnya yang juga untuk menangkap ikan lemuru di Muncar disajikan dalam Tabel 2. Perkembangan yang paling besar adalah bagan, yang daerah operasinya di pinggirpinggir dan biasanya untuk menangkap lemurulemuru kecil (sempenit). Hal ini tentu membahayakan, karena makin banyak ikan-ikan sempenit yang tertangkap akan mempengaruhi produktivitas pukat cincin selanjutnya. Jala eder penurunannya cukup besar, karena merupakan alat yang pasif, tentu kalah bersaing dengan alat-alat yang aktif terutama pukat cincin. Begitu juga halnya dengan alat payang oras yang kenaikannya tidak begitu besar.

Kondisi stok, tingkat upaya penangkapan, dan laju tangkap dari ikan peiagis kecil (termasuk lemuru) yang kesemuanya merupakan bagian aspek managemen memerlukan perhatian khusus sebab spesies ikan ini cenderung sangat sensitif baik terhadap lingkungan maupun mortalitas penangkapan (Tussing,1974). Upaya penangkapan yang berlebihan, pada beberapa perikanan pelagis kecil, telah diikuti dengan cepat oleh kolapsnya rekrutmen dan punahnya stok ikan. Kebanyakan jenis-jenis ikan 
Tabel 1. Perkembangan jumlah pukat cincin di Selat Bali tahun 1993-2002

Table 1. Annual number of purse seine in Bali Strait, 1993-2002

\begin{tabular}{cccccccc}
\hline Tahun & Bali & Muncar & Total & Tahun & Bali & Muncar & Total \\
\hline 1974 & 0 & 10 & 10 & 1989 & $68(83)$ & $190(190)$ & $258(273)$ \\
1975 & 26 & 44 & 70 & 1990 & $72(83)$ & $190(190)$ & $262(273)$ \\
1976 & 43 & 96 & 139 & 1991 & $70(83)$ & $190(190)$ & $260(273)$ \\
1977 & $74(50)$ & $119(50)$ & $193(100)$ & 1992 & $73(83)$ & $190(190)$ & $263(273)$ \\
1978 & $102(60)$ & $122(73)$ & $224(133)$ & 1993 & $73(83)$ & $190(190)$ & $263(273)$ \\
1979 & $106(60)$ & $166(73)$ & $272(133)$ & 1994 & $72(83)$ & $190(190)$ & $262(273)$ \\
1980 & $48(60)$ & $173(73)$ & $221(133)$ & 1995 & $75(83)$ & $190(190)$ & $265(273)$ \\
1981 & $65(60)$ & $185(73)$ & $250(133)$ & 1996 & $76(83)$ & $190(190)$ & $266(273)$ \\
1982 & $78(60)$ & $200(73)$ & $278(133)$ & 1997 & $76(83)$ & $190(190)$ & $266(273)$ \\
1983 & $82(75)$ & $200(125)$ & $282(200)$ & 1998 & $79(83)$ & $140(190)$ & $219(273)$ \\
1984 & $86(75)$ & $200(125)$ & $286(200)$ & 1999 & $78(83)$ & $130(190)$ & $208(273)$ \\
1985 & $86(83)$ & $190(190)$ & $276(273)$ & 2000 & $78(83)$ & $130(190)$ & $208(273)$ \\
1986 & $81(83)$ & $190(190)$ & $273(273)$ & 2001 & $78(83)$ & $133(190)$ & $211(273)$ \\
1987 & $79(83)$ & $190(190)$ & $269(273)$ & 2002 & $78(83)$ & $110(190)$ & $188(273)$ \\
1988 & $76(83)$ & $190(190)$ & $266(273)$ & & & &
\end{tabular}

Sumber: - 1974-1998: Merta et. al. (2000)

- 1999-2002: Dinas Perikanan Kabupaten Banyuwangi dan Propinsi Bali

- Angka dalam kurung adalah jumlah SIUP

Tabel 2. Perkembangan jumlah alat tangkap selain pukat cincin, 1997-2002

Table 2. Annual number of other gears, 1997-2002

\begin{tabular}{clcccccccc}
\hline \multirow{2}{*}{ No. } & $\begin{array}{c}\text { Jenis alat } \\
\text { tangkap }\end{array}$ & \multicolumn{4}{c}{ Jumlah alat tangkap (unit) } & Naik/turun \\
\cline { 3 - 8 } & & $\mathbf{1 9 9 7}$ & $\mathbf{1 9 9 8}$ & $\mathbf{1 9 9 9}$ & $\mathbf{2 0 0 0}$ & $\mathbf{2 0 0 1}$ & $\mathbf{2 0 0 2}$ & (\%) \\
\hline 1 & Payang oras & 115 & 117 & 93 & 105 & 120 & 130 & 2,5 \\
2 & Jala eder & 253 & 348 & 356 & 142 & 142 & 142 & $-10,9$ \\
3 & Bagan & 148 & 166 & 292 & 292 & 284 & 384 & 21,0 \\
4 & Sero & 114 & 117 & 132 & 132 & 132 & 132 & 3,0 \\
\hline
\end{tabular}

Sumber: Dinas Kelautan dan Perikanan Banyuwangi

pelagis kecil yang bergerombol adalah pemakan plankton, menempati "tropic level" yang relatif rendah dan posisi awal dalam rantai makanan di laut. Stokstok ini dapat mencapai tingkat biomassa yang tinggi di daerah di mana terjadi proses upwelling. Hubungannya di dalam rantai makanan biasanya sederhana, misalnya fitoplankton-anchovi, atau fitoplankton-zooplankton-sardin.

Karena sederhananya hubungan dengan komponenkomponen lain dari sistem barangkali dapat membantu menjelaskan mengapa spesies ikan ini cenderung lebih melimpah tetapi lebih mudah berubah dan lebih mudah dipengaruhi oleh perubahan-perubahan pada kondisi lingkungan dibandingkan misalnya ikan-ikan demersal (Csirke, 1977). Oleh karena itu, stok ikan-ikan pelagis kecil bergerombol merupakan stok ikan yang "poorly behaved" dan sangat mudah berubah-ubah, dibandingkan dengan ikan-ikan demersal yang "well behaved". Menurut Gulland (1977a), stok-stok ikan pelagis kecil rupanya sekali sensitif terhadap tekanan penangkapan yang tinggi (heavy fishing).

Saat ini penggunaan "titik-titik acuan" untuk managemen perikanan memperlihatkan tren kuantitatif yang naik. Meskipun begitu, dalam prakteknya, pada kebanyakan yurisdiksi telah terjadi kegagalan mengkonservasi stok-stok untuk penggunaan secara berkelanjutan. Untuk ini ada beberapa alasan (Caddy \& Mahon, 1995) meliputi:

- Tujuan-tujuan pengelolaan tidak ditentukan secara benar.

- Dasar-dasar konsep untuk Titik-titik Acuan tidak ditentukan secara tepat.

- Masalah-masalah mengestimasi Titik-titik Acuan dan status stok (variabilitas).

- Kegagalan dalam menghubungkan pengkajian sumber daya kepada tujuan-tujuan managemen.

- Kesulitan para ilmuwan dalam mengkomunikasikan masalah-masalah ini kepada para pengelola dan stakeholder.

- Kegagalan managemen mendesak perikanan sampai pada tingkat-tingkat yang dapat diterima.

\subsection{Perkembangan produksi}

Sejak tahun 1975 produksi mulai naik dan pada tahun 1976 mencapai 22.739 ton. Kemudian produksi berfluktuasi antara 17.479-27.314 ton antara tahun 
1976-1981. Lalu produksi naik dengan tajam, mencapai puncak pada tahun 1983 sebesar 48.076 ton. Sejak itu produksi menurun dengan tajam mencapai nilai terendah pada tahun 1986 sebesar 4.661 ton. Menurut nelayan, pada tahun tersebut ikan lemuru "menghilang". Hal ini belum diketahui secara pasti, mungkin ada pengaruh dari terjadinya El Nino yang sangat kuat pada tahun 1982-1983.

Dengan jumlah pukat cincin pada tahun 1983 sebanyak 200 unit dan pada tahun 1985 menjadi 273 unit, serta diduga sumber daya ikan lemuru sudah pulih kembali, produksi terus naik dengan tajam dan mencapai puncak pada tahun 1991 yang lebih tinggi dari pada puncak pada tahun 1983, yaitu sebesar 61.669 ton. Kemudian produksi terus menurun sampai mencapai nilai terendah kedua pada tahun 1996, yaitu 10 tahun setelah 1986 sebesar 13.327 ton. Kemudian terjadi lonjakan produksi yang luar biasa, yang dalam dua tahun mencapai nilai tertinggi ketiga, sebesar 77.572 ton, yaitu lebih tinggi dari nilai puncak produksi pada tahun 1991. Menurut Mathews et. al. (2001), Southern Oscillation Index (SOI) berdampak sangat nyata pada produksi ikan lemuru yang didaratkan, dengan tahun-tahun terjadinya El Nino menghasilkan produksi ikan yang didaratkan sangat tinggi, dan tahun-tahun Anti El Nino menghasilkan produksi ikan yang didaratkan sangat rendah (Gambar 1). Produksi ikan lemuru yang tinggi terjadi selama proses-proses El Nino, barangkali karena proses penaikan air (upwelling) yang kuat menstimulasi produksi primer dan sekunder yang tinggi yang diperlukan hari terjadinya rekruitmen dan kelangsungan hidupnya yang tinggi. Tingginya pendaratan lemuru yang terjadi pada tahun-tahun terjadinya El Nino, diduga karena "upwelling" yang kuat menyebabkan terjadinya produktivitas primer dan sekunder yang tinggi yang diperlukan bagi rekruitmen dan kelangsungan hidup yang tinggi dari ikan lemuru.

Kemudian produksi turun lagi dengan tajam mencapai nilai terendah ketiga sebesar 8.286 ton pada tahun 1999. Produksi perlahan-lahan naik lagi dan pada tahun 2002 terjadi lonjakan produksi menjadi 52.000 ton. Apakah produksi pada tahun 2002 akan terus naik atau merupakan puncak keempat, belum dapat diramalkan dengan pasti (Gambar 2).

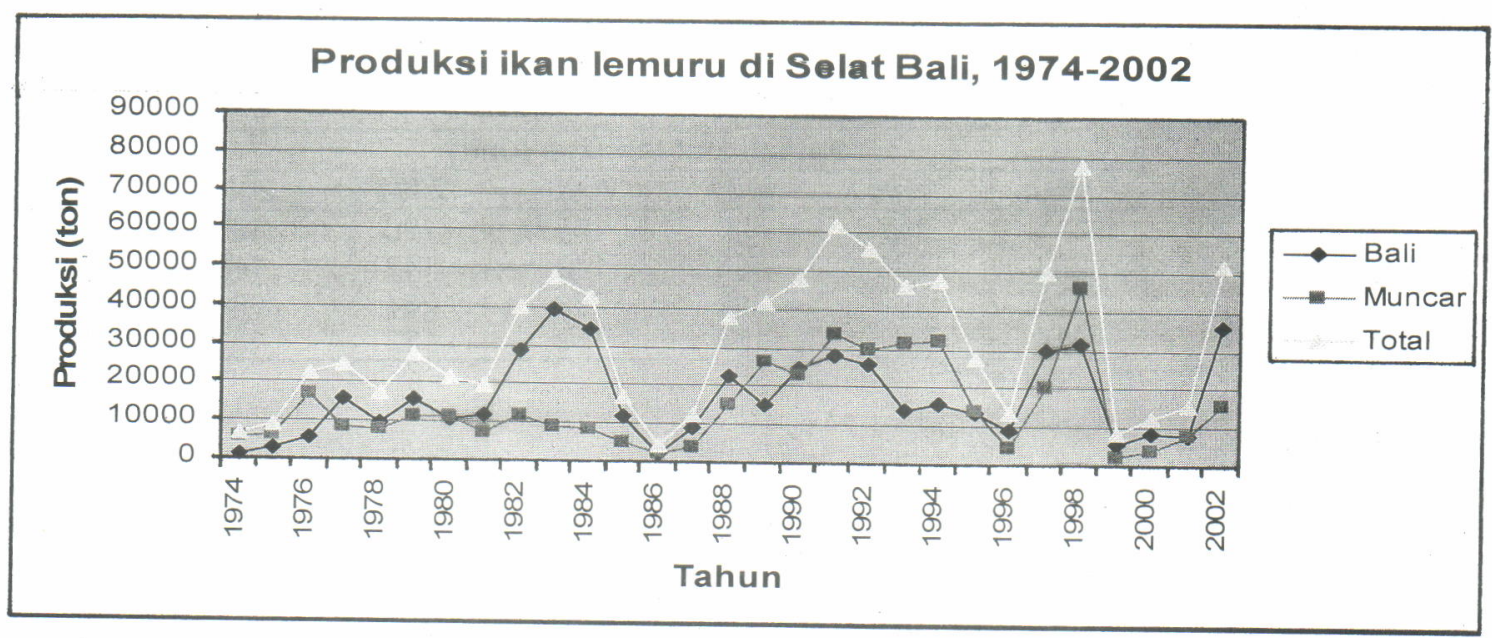

Sumber: Data produksi tahun 1974-1999 dari Merta et.al. (2000) dan tahun 2000-2002 dari Dinas Perikanan dan Kelautan Propinsi Daerah Tingkat I Bali dan Resort Perikanan dan Kelautan Muncar.

Gambar 1. Perkembangan produksi ikan lemuru, Sardinella lemuru Bleeker 1853, di Selat

Figure 1. The development of lemuru, Sardinella lemuru Bleeker 1853, production in Bali Strait.

\subsection{Komposisi hasil tangkapan}

Komposisi hasil tangkapan rata-rata selama lima tahun terakhir (1998-2002) disajikan dalam Tabel 3. Jenis-jenis ikan yang tertangkap dengan pukat cincin sama dengan yang tertangkap dengan jala oras. Karena daerah penangkapan alat payang tidak jauh dengan pukat cincin. Jenis-jenis ikan yang tertangkap dengan bagan juga didominansi oleh lemuru berukuran kecil (sempenit). Di samping itu tertangkap juga ikan layur, teri dan juga ikan-ikan demersal, dalam jumlah sedikit. Alat-alat bagan tancap terutama dipasang di Teluk Pangpang, di mana perairannya dangkal, yang merupakan daerah tempat munculnya ikan-ikan sempenit, sedangkan bagan apung beroperasi di pinggir-pinggir sebelah luar Tanjung Sembulungan.

\subsection{Ukuran ikan yang tertangkap}

Sujastani \& Nurhakim (1982) menunjukkan bahwa terjadi penurunan panjang rata-rata ikan lemuru yang tertangkap dari $17,00(1977,1978)$ menjadi $15,5 \mathrm{~cm}$ (1980). Lebih jauh juga ditunjukkan bahwa panjang 
Tabel 3. Persentase rata-rata komposisi hasil tangkapan pukat cincin, payang oras, dan bagan in Muncar, 1998-2002

Table 3. $\quad$ Average percentage catch composition of purse seine, payang oras, and liftnet in Muncar, 19982002

\begin{tabular}{|c|c|c|c|c|}
\hline No. & Jenis-jenis ikan & Pukat cincin & Payang oras & Bagan \\
\hline 1 & Lemuru & 87,80 & 57,60 & 54,03 \\
\hline 2 & Tembang & 3,34 & 17,02 & 0,0 \\
\hline 3 & Layang & 2,21 & 8,57 & 0,0 \\
\hline 4 & Cumi-cumi & 2,13 & 1,23 & 2,10 \\
\hline 5 & Layur & 1,99 & 7,10 & 20,96 \\
\hline 6 & Tongkol & 1,20 & 2,29 & 0,0 \\
\hline 7 & Kembung & 0,73 & 5,95 & 0,0 \\
\hline 8 & Selar & 0,56 & 0,18 & 0,0 \\
\hline 9 & Teri & 0,0 & 0,0 & 10,51 \\
\hline 10 & Petek & 0,0 & 0,0 & 5,44 \\
\hline 11 & Belanak & 0,0 & 0,0 & 3,91 \\
\hline 12 & Rebon & 0,0 & 0,0 & 1,04 \\
\hline 13 & Lain-lain & 0,04 & 0,06 & 2,01 \\
\hline & $\Sigma$ & 100,00 & 100,00 & 100,00 \\
\hline
\end{tabular}

Sumber: Resort Perikanan dan Kelautan, Muncar

rata-rata pertama kali tertangkap (Lc) dari $15,0 \mathrm{~cm}$ (1977, 1978) menjadi $13,0 \mathrm{~cm}$ (1980). Sumber lain juga menunjukkan adanya penurunan panjang ratarata, yaitu dari $16,61 \mathrm{~cm}$ (1977) menjadi $15,42 \mathrm{~cm}$ (1981) (Dwiponggo et. al., 1986). Merta (1992) menunjukkan bahwa rata-rata ikan lemuru yang tertangkap lebih kecil dari tahun-tahun sebelumnya, yaitu $14,08 \mathrm{~cm}$. Hasil pengumpulan data frekuensi panjang dari alat-alat tangkap pukat cincin, payang oras, dan bagan pada bulan-bulan Maret, April, Mei, dan Juni tahun 2003 sebanyak 2.099 ekor diperoleh panjang rata-rata $13,31 \mathrm{~cm}$. Data tersebut menunjukkan bahwa ukuran rata-rata ikan terus menurun sejak tahun 1977 sampai tahun 2003, meskipun pengumpulan data pada tahun terakhir ini hanya baru empat bulan saja.

Penelitian mengenai biologi reproduksi dari ikan lemuru di Selat Bali sangat kurang, sehingga belum diketahui perkembangan dari panjang rata-rata ikan lemuru pertama kali memijah $\left(I_{m}\right)$ dengan mengecilnya ukuran ikan yang tertangkap.

\subsection{Tingkat pengusahaan}

Sujastani \& Nurhakim (1982) telah melakukan pengkajian stok ikan lemuru di Selat Bali menggunakan Model Produksi Surplus, memperoleh dugaan $M S Y=36,00$ ton dan $\mathrm{f}_{\mathrm{opt}}=190$ unit pukat cincin, menunjukkan bahwa perikanan lemuru di Selat Bali telah mengalami penangkapan yang berlebihan (overfishing). Jumlah pukat cincin yang ada pada tahun yang sama sudah mencapai 278 unit, tetapi jumlah SIUP yang dikeluarkan baru 133 buah. Kemudian dengan menggunakan model analisis yang sama, Martosubroto et. al., (1986), Salim (1986) dan Jurusan Perikanan, Fakultas Peternakan, Universitas Diponegoro (1992), memperoleh dugaan MSY berkisar antara 40.000-80.332 ton dengan $f_{\text {opt }}$ berkisar antara 123-320 unit pukat cincin, juga menyatakan hal yang sama, bahwa perikanan lemuru di Selat Bali sudah mengalami tangkap lebih. Dalam periode yang sama (1986-1992), jumlah pukat cincin yang ada berkisar antara 273-263 unit, sedangkan jumlah SIUP yang ada sejak 1985-1992 tetap 273 buah. Jelasnya dapat dilihat dalam Tabel 4.

Mathews et. al. (2001) mencoba menganalisis perikanan lemuru menggunakan Model Produksi Surplus dengan menambahkan SOI (Southern Oscillation Index) sebagai perubah lingkungan dan diselesaikan melalui program CLIMPROD, menunjukkan bahwa perikanan lemuru dieksploitasi jenuh (fully exploited) selama tahun-tahun terjadinya El Nino, dan mengalami penangkapan yang sangat berlebihan (very highly exploited) pada tahun-tahun Anti EI Nino. Meskipun perikanan lemuru di Selat Bali pada saat sekarang ini dipanen dengan sangat berat (very heavily harvested), tetapi dengan adanya proses penaikan air (upwelling) adalah mungkin bahwa perikanan lemuru di daerah ini belum dibatasi oleh sumber dayanya.

Tabel 4. Jumlah pukat cincin, SIUP, dan dugaan MSY dan $\mathrm{f}_{\mathrm{opt}}$ menggunakan model-model produksi surplus

Table 4. Number of purse seine, SIUP, and estimated MSY and $f_{\text {opt }}$ using surplus production models

\begin{tabular}{lcccc}
\multicolumn{1}{c}{ Penulis / Tahun } & $\begin{array}{c}\text { Jumlah } \\
\text { Purse seine }\end{array}$ & $\begin{array}{c}\text { Jumlah } \\
\text { SIUP }\end{array}$ & MSY & f fopt $^{\text {Pur }}$ \\
\hline Sujastani \& Nurhakim (1982) & 278 & 133 & 36.000 & 190 \\
Martosubroto, Naamin \& Nurhakim (1986) & 273 & 273 & $62.317-66.306$ & $238-242$ \\
Salim (1986) & 273 & 273 & $47.512-80.332$ & $123-320$ \\
Jur. Perikanan, Fak. Nak., UNDIP (1992) & 263 & 273 & 40.000 & 180 \\
\hline
\end{tabular}


Tingkat pengusahaan yang telah terjadi pada perikanan lemuru ini juga lebih diperkuat lagi dengan analisis menggunakan Model Y/R Beverton dan Holt oleh Ritterbush (1975), bahwa telah terjadi penangkapan yang jenuh (fully exploited). Puluhan tahun kemudian, Gumilar (1985) juga menggunakan Model Y/R Beverton dan Holt dan Merta (1992) menggunakan Model Y/R Jones, juga menunjukkan bahwa telah terjadi lebih tangkap, begitu juga menggunakan Model Thompson dan Bell (Merta \& Eidman, 1994).

\section{KESIMPULAN DAN SARAN}

\section{Kesimpulan}

Upaya pemerintah untuk mengelola perikanan lemuru di Selat Bali, melalui pembatasan jumlah alat dan ukuran alat tangkap pukat cincin serta besar mata jaring pada bagian kantong, tidak berjalan sebagaimana diharapkan. Ini terutama disebabkan karena MCS dan penegakan hukum dari pelaksanaan peraturan-peraturan yang dikeluarkan tidak berjalan secara optimal. Di samping itu, juga diduga faktor lingkungan (seperti El Nino dan La Nina) juga berperan, sehingga lebih menyulitkan pencapaian tujuan dari pengelolaan tersebut.

\section{Saran}

\begin{abstract}
Penegakan hukum dalam melaksanakan peraturan-peraturan yang telah diundangkan dilaksanakan secara konsekuen, dengan memberikan sangsi kepada yang tidak mematuhinya. MCS perlu ditegakkan untuk memantau dan mengendalikan aktivitas-aktivitas yang merugikan. Mencegah makin bertambah besarnya kekuatan mesin-mesin yang digunakan, dengan demikian berarti mencegah "stuffing" kapital.
\end{abstract}

Perlu segera diterbitkan Peraturan Pemerintah (PP) yang menggantikan Peraturan Pemerintah No. 10 Tahun 1998, yang menghentikan restribusi terhadap hasil tangkapan yang didaratkan di TPI, baik di Muncar (Banyuwangi) maupun di Pengambengan (Bali), sehingga TPI berfungsi kembali secara normal.

\section{DAFTAR PUSTAKA}

Barus, H.R. \& Ch. Nasution. 1982. Purse seine sebagai alat tangkap ikan lemuru (Sardinella longiceps) di Selat Bali. Pros. Seminar Perikanan Lemuru, Banyuwangi, 18-21 Januari 1982. Puslitbangkan, Jakarta. Hal. 13-26.

Caddy, J.F. \& R. Mahon. 1995. Reference points for fisheries management. FAO Fish. Tech. Pap., (347):83.

Csirke, J. 1988. Small Shoaling Fish Stocks. In J.A. Gulland, ed. Fish Population Dynamics. $2^{\text {nd }}$ Ed. John Wiley \& Sons, Chichester. P. 271-302.
Dwiponggo, A., T. Hariati, S. Banon, M.L. Palomares \&. D. Pauly. 1986. Growth, mortality and recruitment of commercially important fishes and penaeid shrimps in Indonesian waters. ICLARM Technical Reports 17. RIMF, Jakarta and ICLARM, Manila. $91 \mathrm{p}$.

FAO/FISHCODE. 2001. Report on a workshop to refine the draft management plan for the Bali Strait sardine (lemuru) fishery. Banyuwangi (East Java), Indonesia. 15-17 May 2001. FAO FISHCODE GCP/INT/648/NOR. Field Report F-18 (En). FAO, Rome. 33 p.

Garcia, s. \& A. Demetropoulos. 1986. Management of Cyprus Fisheries. FAO Fish. Tech. Pap., (250):40.

Ghofar, A., C.P. Mathews, IG.S. Merta, \& S. Salim. 2000. Incorporating the Southern Oscillation Indices to the management model of the Bali Strait sardinella fishery. In FAO/FISHCODE. Papers Presented at the Workshop on the Fishery and Management of Bali Sardinella (Sardinella lemuru) in Bali Strait. FAO, UN, Rome. P. 43-51.

Gulland, J.A. 1968. The concept of the maximum sustainable yield and fishery management. FAO Fish. Tech. Pap., (70):13.

1971. Management. IOFC/DEV/71/4. 8 p.

1972. Some introductory guidelines to management of shrimp fisheries. IOFC/DEV/72/24. FAO, Rome. $12 \mathrm{p}$.

1974a. The management of marine fisheries. Bristol: Scientechnica (Publishers) Ltd. FAO, Rome. 198 p.

management. IOFC/DEV/74?36. 84 p.

1974b. Guidelines for fishery 1977 Goals and objectives of fishery management. FAO Fish. Tech. Pap., (166):14.

1977a. The Problem of population dynamics and contemporary fisheries management. In Fish Population Dynamics: The Implication for Management, J.A. Gulland, ed. $2^{\text {nd }}$ ed. A Wiley Interscience Publication. John Wiley \& Sons, Chichester. P. 383-406.

1980. Some problems of the management of shared stocks. FAO Fish. Tech. Pap., (206):22.

1983. Stock assessment: Why? FAO Fish. Circ., (759):18

Gumilar, A. 1985. Tingkat upaya penangkapan ikan lemuru (Sardinella longiceps C.V.) di perairaan 
Selat Bali. Karya IImiah. Fak. Perikanan, IPB, Bogor. 61 hal. Tidak Dipublikasikaan.

Hill, B.J. 1990. Keynote adress:Minimum legar sizes and their use in management of Australian fisheries. In D.A Hancock, ed. legar sizes and their use in fisheries management. Australian society for fish biology workshop, Lorne, 24 August 1990. Bureau of Rural Resources Proceedings No. 13. (Australian Government Publsihing Service, Canberra.)

Jurusan Perikanan, Fakultas Perikanan UNDIP. 1992. Studi penyusunan dan penataan zona penangkapan perikanan industri dan skala kecil di perairan Selat Bali. Laporan Akhir. Proyek Pengembangan Desa Pantai, Ditjenkan, Deptan, Jakarta. 95 hal.

King, M. 1995. Fisheries Biology, Assessment and Management. Fishing News Books, London. 341 p.

Kusuma, A.A.G.R.A. 1980. Suatu studi tentang design dan teknik penangkapan purse seine lemuru di perairan Selat Bali. Karya IImiah. Fak. Perikanan, IPB., Bogor. 144 hal. Tidak Dipublikasikan.

MacKenzie, W.C. 1992. An introduction to the economics of fisheries management. FAO Fish. Tech. Pap., (226):31.

Martosubroto, P., N. Naamin \& S. Nurhakim. 1986. Menuju managemen perikanan lemuru yang rasional. Jurnal Penelitian Perikanan Laut, (35):5966.

2001. Introduction to fisheries management. In FAO/FISHCODE. Report on a Workshop to Refine the Draft Management Plan for the Bali Strait Sardine (Lemuru) Fishery. Banyuwangi, (East Java), Indonesia. 15-17 May 2001. FAO/FISHCODE/ GCP/INT/648/NOR Field Report F-18 (En), Rome, FAO, 2001. 33 p.

Merta, I G.S. 1989. Beberapa alternatif pengelolaan perikanan lemuru, Sardinella longiceps Valenciennes 1847 (Pisces: Clupeidae) di Perairan Selat Bali. J. Lit. Kan. Laut, (52):35-44.

Merta, I G.S. 1992. Dinamika Populasi Ikan Lemuru, Sardinella lemuru Bleeker 1853 (Pisces:Clupeidae) di Perairan Selat Bali dan Alternatif Pengelolaannya. Disertasi. Fakultas Pascasarjana, IPB. 201 hal. Tidak dipublikasikan.

K. Widana, Yunizal \& R. Basuki. 2000. Status of the lemuru fishery in Bali Strait. Its development and Prospects. In FISHCODE MANAGEMENT. GCP/INT/648/NOR. Field Report F-3-Supp. (En). FAO, Rome. P. 1-41.
Mathews, C.P., A. Ghofar, G.S. Merta, N. Hendiarti \& H. Lestiana. 2001. Effects of frontal systems, upwelling, and $\mathrm{EI}$ Nino on the small pelagic fisheries of the Lesser Sunda Islands, Indonesia. In Proceeding. The First International Symposium on Geographic Information Systems (GIS) in Fishery Science (Seattle, Washington, U.S.A.; 2-4 March 1999), Eds. By T. Nishida, P.J. Kailola and C.E. Hollingworth. Fish. GIS Res. Group, Saitama, Japan. Pp. 65-88.

Panayotou, T. 1982. Management concepts for smallscale fisheries: Economic and Social Aspects. FAO Fish. Tech. Pap., (228):53.

Parsons, L.S. 1980. Fisheries management and regulatory measures. In CIDA/FAO/CECAF, Selected Lectures from the CIDA/FAO/CECAF. Seminar on Fishery Resource Evaluation. Casablanca, Morocco, 6-24 Maret 1978. FAO, Rome, Canada Funds-in-Trust, FAO/TF/INT 180(c)(CAN)Suppl.:153-166.

Pitcher, T.J. \& P.J.B. Hart. 1982. Fisheries Ecology. Croom Helm, London . 414 p.

Rothschild, B.J. 1971. A systems view of fishery management with some notes on the tuna fisheries. FAO Fish. Tech. Pap., (106):33.

Sadhotomo, B. 1991. Dampak Penangkapan ikan muda terhadap produktivitas perikanan (simulasi kasus perikanan lemuru, Sardinella longiceps) di Selat Bali. BPPL, (60):51-66.

Salim, S. 1986. Assessment of the Lemuru (Sardinella longiceps) Fishery in the Bali Strait, Indonesia. M.Sc. Dissertation. School of Anim. Biol., Univ. Coll.North Wales, Bangor, U.K. 52 p.

S.K Menteri Pertanian No. 123/KPTS/UM/3/1975 tentang Ketentuan Mata Jaring Purse Seine.

SK Gubernur KDH Tingkat I Jawa Timur dan Bali No. 238 Tahun 1992/674 Tahun 1992 tentang Pengaturan/Pengendalian Penggunaan Purse Seine di Selat Bali.

Sujastani, T. \& S. Nurhakim. 1982. Potensi Sumber daya perikanan lemuru (Sardinella longiceps) di Selat Bali. Pros. Seminar Perikanan Lemuru. Banyuwangi, 18-21 1982. Pusat Penelitian dan Pengembangan Perikanan, Jakarta. Hal. 1-11.

Tait, R.V. 1981. Elements of Marine Ecology. An Introduction Course. $3^{\text {rd }} \mathrm{Ed}$. Butterworths, London. $356 \mathrm{p}$.

Tussing, A.R. 1974. Fishery Management Issues in the Indian Ocean. IOFC/DEV/74/35. FAO, Rome. $39 \mathrm{p}$. 


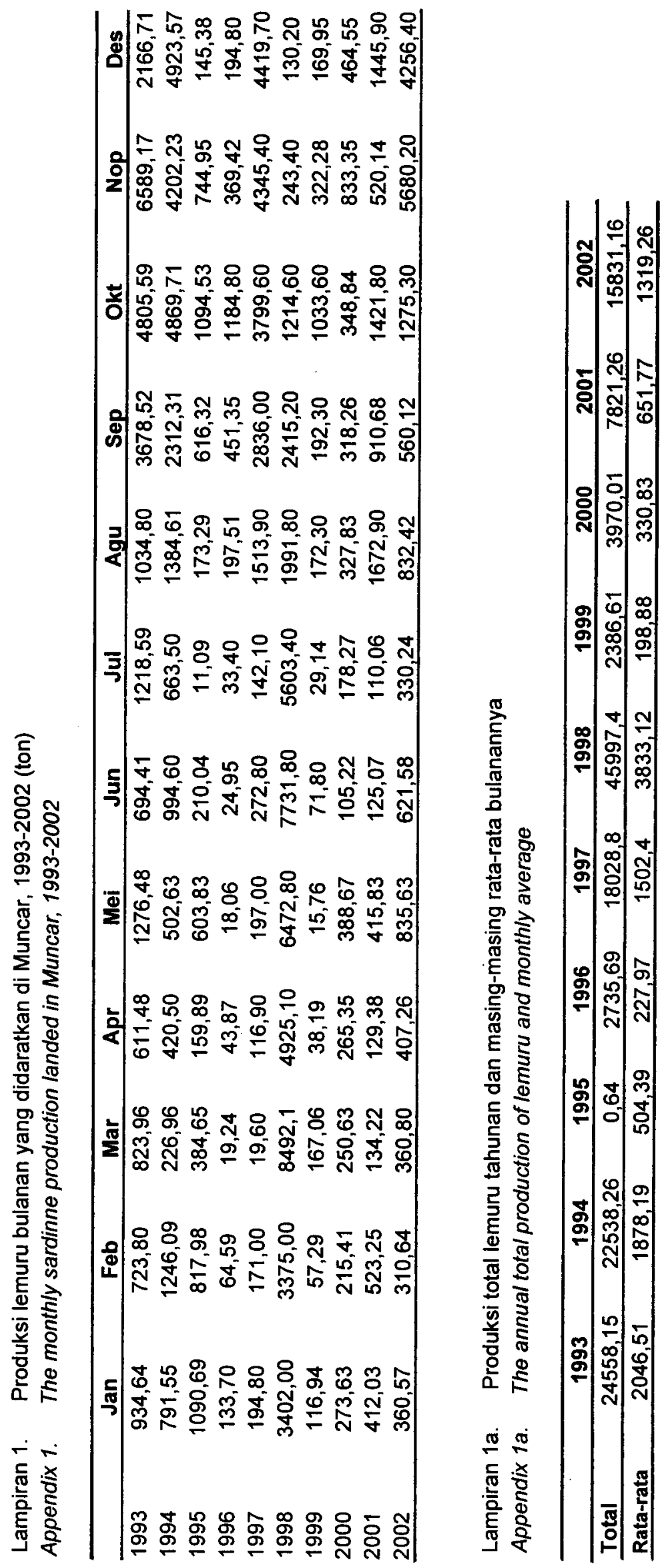




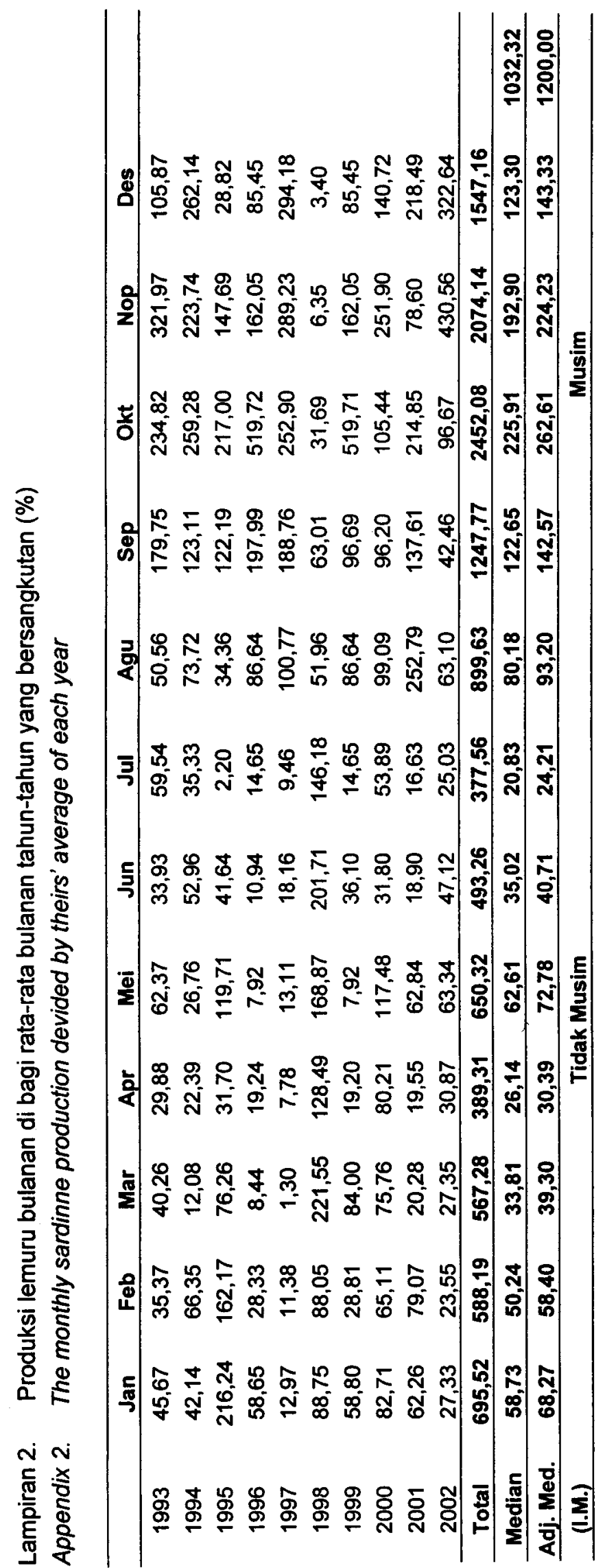


